\title{
Comments on "Analysis of the effect of freeze-thaw cycles on the degradation of mechanical parameters and slope stability"
}

\author{
Zoran Berisavljević $^{1}$ (D)
}

Received: 9 February 2017 / Accepted: 1 April 2017 /Published online: 20 April 2017

(C) Springer-Verlag Berlin Heidelberg 2017

\section{Introduction}

The authors have addressed a very interesting topic regarding the influence of freeze-thaw effects on physicomechanical properties of granitic rock mass in cold regions. Overall, 24 samples were divided into 4 groups of 6 samples and tested under uniaxial compression after $0,10,20$ and 30 freeze-thaw cycles. Results showed that with an increase in the number of cycles, uniaxial compressive strength (UCS) and deformation properties (elastic Young's modulus) decrease. These conclusions were subsequently used to perform slope stability analyses by using MIDAS/GTS FEM software. One of the results of the study is related to the reduction of the safety factor value from 3.73 (for 0 freeze-thaw cycles) to 1.81 (after 30 cycles).

\section{Comments on laboratory test results}

Figure 1 of the paper shows stress-strain curves of granite specimens after exposure to $0,10,20$, and 30 freeze-thaw cycles. It is interesting to note that this is the only data available regarding testing in laboratory conditions. It is not clear whether these curves describe the behavior of a particular sample within one group, or if all samples from one group exhibit exactly the same stress strain curve.

It is important to show the figures of samples prior to and after the testing. Comments regarding macro-cracking of samples after each freeze-thaw cycle should be presented, i.e. whether the sample suffered from cracking or not. If so, the

Zoran Berisavljević

z.berisavljevic@koridorisrbije.rs

1 Koridori Srbije Ltd., 21 Kralja Petra Street, Belgrade 11000, Serbia value of UCS obtained on a previously cracked sample is not a relevant parameter any more and should be excluded from further consideration.

The average values of specific parameters are only shown In Table 1. An additional column (or table) should be included with a set of UCS values obtained for each individual specimen (or the range of values).

\section{Comments regarding stability analyses}

It is not clear how parameters of the Hoek and Brown criterion were determined. No information exists about adopted GSI value. Should this value be the same for the rock mass after 0 and, e.g., 30 freeze-thaw cycles (this value changes in the field scale with deterioration of the rock mass as new cracks are being formed and the surface quality is being reduced)? Information regarding the adopted $m_{i}$ value is also missing. What is the influence of freeze-thaw effects on this parameter? Value of parameter $D$ ? Linear Mohr-Coulomb parameters should be related to the minor principal stress level.

Another comment is related to the longevity of freeze-thaw effects in laboratory and field conditions. The samples in laboratory conditions were exposed to freezing for only $4 \mathrm{~h}$, whereas the rock mass in natural environment could be exposed to freezing for as long as 7 months. Additional comment regarding this issue would add value to the paper.

Comment regarding the process for determining the safety factor value has to be included in the paper. Is this a strength reduction concept or some other?

Probably, the most important comment of this discussion is related to the zone of freeze-thaw influence in numerical analysis. In the section "Overview of the engineering and numerical model," it is stated that the maximum freezing depth is more than $2.2 \mathrm{~m}$. Below that depth, freezing should not have 
any (or should have limited) influence. Slope stability analyses have been performed by assuming that the whole rock mass is influenced by freezing and thawing effects. This is the reason why deep-seated hypothetical failure surfaces have been obtained. The proper way would be to introduce an artificial layer, approx. $2.2 \mathrm{~m}$ thick, at the face of the excavation. In this way, the zone of influence would be restricted to superficial parts of the excavation, which resembles reality more adequately. Deep failure zones (approx. $30 \mathrm{~m}$ deep) could not be the consequence of freeze-thaw effects solely. Displacement plots and plots of plastic points would give additional information regarding the mechanism of failure.

What is the value of tensile strength of the rock material? Failure in tension could be expected in the upper part of the slope if small or no tensile strength was introduced. Shear strain "progression" along the failure surface is not the consequence of rock mass deterioration, but rather the values of input parameters. In order for progressive failure to take place, a coupled hydro-mechanical approach has to be used (Potts and Zdravkovic 2001), i.e. consolidation analysis for which the time effects could be taken into account.

\section{Reference}

Potts DM, Zdravkovic L (2001) Finite element analysis in geotechnical engineering. Application. Thomas Telford Ltd., London 